\title{
Article \\ C-Reactive Protein and White Blood Cell Count in Non-Infective Acute Ischemic Stroke Patients Treated with Intravenous Thrombolysis
}

\author{
Marcin Wnuk ${ }^{1,2, *(\mathbb{D}}$, Justyna Derbisz ${ }^{1,2}$, Leszek Drabik $^{3,4}\left(\mathbb{D}\right.$ and Agnieszka Slowik ${ }^{1,2}$ \\ 1 Department of Neurology, Jagiellonian University Medical College, 31-688 Krakow, Poland; \\ justyna.derbisz@gmail.com (J.D.); slowik@neuro.cm-uj.krakow.pl (A.S.) \\ 2 University Hospital in Krakow, 30-688 Krakow, Poland \\ 3 Department of Pharmacology, Jagiellonian University Medical College, 31-531 Krakow, Poland; \\ leszek.drabik@uj.edu.pl \\ 4 John Paul II Hospital, Krakow, 31-202 Krakow, Poland \\ * Correspondence: marcin.wnuk@uj.edu.pl
}

Citation: Wnuk, M.; Derbisz, J.; Drabik, L.; Slowik, A. C-Reactive Protein and White Blood Cell Count in Non-Infective Acute Ischemic Stroke Patients Treated with Intravenous Thrombolysis. J. Clin. Med. 2021, 10, 1610. https://doi.org/ $10.3390 /$ jcm10081610

Academic Editor: Hyo Suk Nam

Received: 12 March 2021

Accepted: 7 April 2021

Published: 10 April 2021

Publisher's Note: MDPI stays neutral with regard to jurisdictional claims in published maps and institutional affiliations.

Copyright: (c) 2021 by the authors. Licensee MDPI, Basel, Switzerland. This article is an open access article distributed under the terms and conditions of the Creative Commons Attribution (CC BY) license (https:// creativecommons.org/licenses/by/ $4.0 /)$.

\begin{abstract}
Background: Previous studies on inflammatory biomarkers in acute ischemic stroke (AIS) produced divergent results. We evaluated whether C-reactive protein (CRP) and white blood cell count (WBC) measured fasting 12-24 h after intravenous thrombolysis (IVT) were associated with outcome in AIS patients without concomitant infection. Methods: The study included 352 AIS patients treated with IVT. Excluded were patients with community-acquired or nosocomial infection. Outcome was measured on discharge and 90 days after stroke onset with the modified Rankin scale (mRS) and defined as poor outcome (mRS 3-6) or death (mRS =6). Results: Final analysis included 158 patients (median age 72 years (interquartile range 63-82), 53.2\% ( $n=84)$ women). Poor outcome on discharge and at day 90 was 3.8-fold and 5.8-fold higher for patients with CRP $\geq 8.65 \mathrm{mg} / \mathrm{L}$ (fifth quintile of CRP), respectively, compared with first quintile $(<1.71 \mathrm{mg} / \mathrm{L})$. These results remained significant after adjustment for potential confounders (odds ratio (OR) on discharge $=10.68,95 \% \mathrm{CI}$ : 2.54-44.83, OR at day 90 after stroke $=7.21,95 \%$ CI: 1.44-36.00). In-hospital death was 6.3-fold higher for patients with fifth quintile of CRP as compared with first quintile and remained independent from other variables $(\mathrm{OR}=4.79,95 \% \mathrm{CI}$ : 1.29-17.88). Independent predictors of 90-day mortality were $\mathrm{WBC}<6.4 \times 10^{9} / \mathrm{L}(\mathrm{OR}=5.00,95 \% \mathrm{CI}$ : 1.49-16.78), baseline National Institute of Health Stroke Scale (NIHSS) score (OR = 1.13 per point, $95 \%$ CI: $1.01-1.25$ ) and bleeding brain complications $(\mathrm{OR}=5.53,95 \% \mathrm{CI}: 1.59-19.25)$ but not CRP $\geq 8.65 \mathrm{mg} / \mathrm{L}$. Conclusions: Non-infective CRP levels are an independent risk factor for poor short- and long-term outcomes and in-hospital mortality in AIS patients treated with IVT. Decreased WBC but not CRP is a predictor for 90-day mortality.
\end{abstract}

Keywords: stroke; thrombolysis; C-reactive protein; white blood cell count; prognosis; outcome

\section{Introduction}

Numerous biomarkers [1,2], including inflammatory ones, were found to be associated with atherosclerosis and cardiovascular events [3]. This applied to the levels of C-reactive protein (CRP) which increase during the first $24 \mathrm{~h}$ after hospital admission was independently associated with an increased risk of 30-day mortality in patients with acute myocardial infarction [4]. Increased white blood cell count (WBC) was instead an independent risk factor for long-term mortality in patients with coronary artery disease [5].

In patients with acute ischemic stroke (AIS) treated with intravenous thrombolysis (IVT), CRP within $24 \mathrm{~h}$ from symptom onset [6] and WBC within $24 \mathrm{~h}$ after IVT [7] were associated with a poor long-term functional outcome. However, there were also numerous studies which produced divergent results concerning the prognostic role of CRP in patients with AIS, likely due to a high proportion of patients with an infection. The negative 
prognostic influence of CRP was not ameliorated by IVT [8], whereas in several studies other prognostic factors were found to be more important in long-term prognosis [9-11]. It was shown that from 18.2 [12] to $23.6 \%$ [13] of AIS patients developed an infection during hospitalization, with pneumonia and urinary tract infection being the most common [14]. Although the elevation of inflammatory markers is usually observed in infections, a CRP increase in AIS may reflect non-infective ischemia-induced inflammation contributing to a hypercoagulable state and extensive tissue damage [15]. There is no widely accepted cut-off point in the literature for infective CRP in the AIS studies $[9,16]$. Although the specific cut-off value $(>6 \mathrm{mg} / \mathrm{dL})$ was used to exclude possible concomitant infection in a study by Montaner et al. [8], the clinical assessment plays a more important role in the exclusion of infection. Therefore, previous studies might have produced inconsistent findings of the prognostic role of CRP in AIS patients due to the variable and inadequate threshold of a biomarker used. CRP level and WBC may also be affected by measurements which took place in different clinical conditions, such as different time of the day, after previous food intake and under the influence of non-steroidal anti-inflammatory drugs [17-19]. For example, fasting is associated with a significant decrease in the CRP level [17], whereas WBC increases by nearly $10 \%$ two hours after meal consumption [19].

Many factors, including age, comorbidities and severity as measured with the National Institute of Health Stroke Scale (NIHSS) affect long-term prognosis after AIS treated with IVT [20]. There is still a need for other markers which could help predict long-term prognosis among AIS patients.

Therefore, the aim of the current study was to evaluate whether CRP levels and WBC measured fasting $12-24 \mathrm{~h}$ after IVT were associated with short- and long-term outcome in AIS patients without concomitant infection.

\section{Materials and Methods}

\subsection{Patient Recruitment, CRP and WBC Measurements}

The study was performed as a retrospective analysis of the prospectively collected data of 352 AIS patients from the Krakow Stroke Data Bank, a single-center stroke registry established in the University Hospital in Krakow in 2007. All patients were of Caucasian origin and were treated with IVT between June 2014 and December 2018. Excluded were patients with infection $(n=83)$ as described previously [13]. The lack of infection was determined by the exclusion of patients with fever, signs of infection in the physical examination, or those who needed antibiotics during subsequent hospitalization. Moreover, all patients underwent a routine chest $x$-ray, urine test and internal medicine consultation during the first 3 days since admission. Additionally, follow-up internal medicine consultation was performed in case of CRP elevation and before discharge. As the presence of malignant tumor was the exclusion criteria for IVT in AIS, there were no patients with this condition enrolled in our study.

After further exclusion of patients without available information regarding CRP and WBC levels measured fasting between 12 and $24 \mathrm{~h}$ after IVT, there were 158 remaining patients included in the final analysis. Our institutional protocol for fasting blood measurements requires overnight fasting for at least $6 \mathrm{~h}$ [21] and blood withdrawal before breakfast between 7 and 8 a.m. [22].

We collected the data about demographics, vascular risk factors, stroke etiology and NIHSS on admission and after IVT. Patients were followed-up according to the previously described protocol [13]. Outcome was measured with the modified Rankin scale (mRS). We obtained information about prognosis on discharge and 90 days after stroke onset and defined as poor outcome (mRS 3-6) or death $(\mathrm{mRS}=6)$. Bleeding brain complications secondary to IVT were defined according to the ECASS-1 classification [23,24].

The study was approved by the Jagiellonian University Ethical Committee (KBET 54/B/2007). We obtained informed consent from all patients which was either written or verbal in the presence of at least two physicians in case of the inability to use the dominant hand due to stroke. 


\subsection{Statistics}

The study was powered to have an $80 \%$ chance to detect a $50 \%$ difference in CRP between the group with mRS $0-2$ and 3-6 at the 0.05 significance level. In order to demonstrate such a difference or greater, 26 subjects or more were required in each group based on the values from a published article [16].

The baseline clinical characteristics according to the quintiles of CRP and quartiles of WBC were compared using the univariate analysis of variance, Kruskal-Wallis rank ANOVA and chi-squared test, as appropriate. Values were presented as counts and percentages, means and standard deviations or medians (interquartile ranges), as appropriate. The multivariate models included age, sex and body mass index (BMI) (model 1); age, sex, BMI, hypertension, $\mathrm{mRS}$ score before stroke $>0$, baseline NIHSS score, hemorrhagic brain complications and fasting hyperglycemia (model 2A); and age, sex, BMI, hypertension, maximal systolic blood pressure within $24 \mathrm{~h}$ after IVT, $\mathrm{mRS}$ score before stroke $>0$, baseline NIHSS score, hemorrhagic brain complications and mechanical thrombectomy (model 2B). The Hosmer-Lemeshow test and ROC (Receiver Operating Characteristic) scores were used to evaluate the goodness of fit. Models with the lowest Akaike information criterion and highest Nagelkerke pseudo R2 were presented. The level of significance was set at a $p$-value $\leq 0.05$. The data were processed using STATISTICA version 13.0 (Statsoft Inc., Tulsa, OK, USA).

\section{Results}

\subsection{Patient Characteristics, Serum CRP Levels and WBC 12-24 h after IVT}

The cohort of 158 patients with AIS treated with IVT is presented in Table 1 according to the CRP quintiles. The median age was 72 years (interquartile range 63-82), and 53.2\% $(n=84)$ of patients were women. Mechanical thrombectomy was performed in $47(29.7 \%)$ patients.

Table 1. Baseline clinical characteristics of the patients based on C-reactive protein (CRP) quintiles.

\begin{tabular}{|c|c|c|c|c|c|c|}
\hline & $\begin{array}{c}\mathrm{Q} 1 \\
\mathrm{CRP}<1.71 \\
(n=32)\end{array}$ & $\begin{array}{c}\mathrm{Q} 2 \\
\text { CRP 1.71-3.11 } \\
(n=32)\end{array}$ & $\begin{array}{c}\mathrm{Q3} \\
\text { CRP 3.12-5.09 } \\
(n=31)\end{array}$ & $\begin{array}{c}\mathrm{Q} 4 \\
\text { CRP 5.10-8.64 } \\
\quad(n=32)\end{array}$ & $\begin{array}{c}\mathrm{Q5} \\
\mathrm{CRP} \geq 8.65 \\
(n=31)\end{array}$ & $p$-Value \\
\hline Age (years) & $68(58-76)$ & $73(68-80)$ & $73(69-80)$ & $72(64-83)$ & $77(62-86)$ & 0.246 \\
\hline Women, $n(\%)$ & $15(46.9)$ & $15(46.9)$ & $14(45.2)$ & $19(59.4)$ & $21(67.8)$ & 0.292 \\
\hline BMI $\left(\mathrm{kg} / \mathrm{m}^{2}\right)$ & $24.7(22.8-27.7)$ & $24.8(23.3-27.7)$ & $27.5(24.2-29.3)$ & $27.1(25.2-29.9)$ & $26.8(25.0-29.7)$ & 0.006 \\
\hline Hypertension, $n(\%)$ & $22(68.8)$ & $23(71.2)$ & $27(87.1)$ & $26(81.2)$ & $30(96.8)$ & 0.031 \\
\hline $\begin{array}{c}\text { Hypercholesterolemia, } \\
n(\%)\end{array}$ & $12(37.5)$ & $8(25.0)$ & $11(35.5)$ & $1134.4)$ & $6(19.4)$ & 0.461 \\
\hline $\begin{array}{c}\text { Diabetes mellitus, } n \\
(\%)\end{array}$ & $9(28.1)$ & $8(25.0)$ & $7(22.6)$ & $7(21.9)$ & $11(35.5)$ & 0.744 \\
\hline Smoking, $n(\%)$ & $6(18.8)$ & $2(6.3)$ & $2(6.5)$ & $8(25.8)$ & $5(16.1)$ & 0.151 \\
\hline $\begin{array}{c}\text { Ischemic heart disease, } \\
n(\%)\end{array}$ & 7 (21.9) & $3(9.4)$ & $7(22.6)$ & $10(31.2)$ & $8(25.8)$ & 0.307 \\
\hline Atrial fibrillation, $n(\%)$ & $6(18.8)$ & $10(31.3)$ & $11(35.5)$ & $8(25.0)$ & $9(29.0)$ & 0.635 \\
\hline Previous stroke, $n(\%)$ & $7(21.9)$ & $3(9.4)$ & $8(25.8)$ & $6(18.8)$ & $4(12.9)$ & 0.432 \\
\hline $\begin{array}{c}\text { mRS score before } \\
\text { stroke }>0\end{array}$ & $3(9.4)$ & $1(3.1)$ & $1(3.2)$ & $4(12.5)$ & $2(6.4)$ & 0.523 \\
\hline Stroke etiology, $n(\%)$ & & & & & & \\
\hline -large-vessel disease & $5(15.6)$ & $5(15.6)$ & $5(16.1)$ & $3(9.4)$ & $5(16.1)$ & \\
\hline -small-vessel disease & $1(3.1)$ & $1(3.1)$ & $0(0.0)$ & $0(0.0)$ & $0(0.0)$ & \\
\hline -cardioembolic & $6(18.8)$ & $11(34.4)$ & $12(38.7)$ & $11(34.4)$ & $10(32.3)$ & 0.932 \\
\hline -other & $19(59.4)$ & $14(43.8)$ & 13 (41.9) & $18(56.3)$ & $15(48.4)$ & \\
\hline - undetermined & $1(3.1)$ & $1(3.1)$ & $1(3.2)$ & $0(0.0)$ & $1(3.2)$ & \\
\hline
\end{tabular}


Table 1. Cont.

\begin{tabular}{|c|c|c|c|c|c|c|}
\hline & $\begin{array}{c}\mathrm{Q} 1 \\
\mathrm{CRP}<1.71 \\
(n=32)\end{array}$ & $\begin{array}{c}\mathrm{Q} 2 \\
\text { CRP } 1.71-3.11 \\
(n=32)\end{array}$ & $\begin{array}{c}\mathrm{Q3} \\
\text { CRP 3.12-5.09 } \\
(n=31)\end{array}$ & $\begin{array}{c}\mathrm{Q} 4 \\
\text { CRP 5.10-8.64 } \\
\quad(n=32)\end{array}$ & $\begin{array}{c}\mathrm{Q5} \\
\mathrm{CRP} \geq 8.65 \\
(n=31)\end{array}$ & $p$-Value \\
\hline $\begin{array}{c}\text { Mechanical } \\
\text { thrombectomy, } n(\%)\end{array}$ & $5(15.60$ & $8(25.0)$ & $10(32.3)$ & $11(34.4)$ & $13(41.9)$ & 0.198 \\
\hline $\begin{array}{l}\text { Time from stroke onset } \\
\text { to thrombolysis ( } \mathrm{min} \text { ) }\end{array}$ & $119(94-175)$ & 145 (93-174) & 117 (85-174) & $90(76-176)$ & $121(83-160)$ & 0.556 \\
\hline $\begin{array}{l}\text { NIHSS score on } \\
\text { admission }\end{array}$ & $9.7 \pm 6.3$ & $9.2 \pm 6.7$ & $12.5 \pm 6.9$ & $11.6 \pm 6.3$ & $14.6 \pm 6.4$ & 0.013 \\
\hline $\begin{array}{l}\text { NIHSS score after r-tPA } \\
\text { Post-IVT hemorrhagic } \\
\text { brain complications, } n\end{array}$ & $4.4 \pm 4.6$ & $5.3 \pm 5.5$ & $8.1 \pm 9.7$ & $5.7 \pm 6.9$ & $11.9 \pm 8.7$ & $<0.001$ \\
\hline$(\%)$ & $29(90.6)$ & $27(84.4)$ & $25(80.7)$ & $27(84.4)$ & $22(71.0)$ & \multirow{5}{*}{0.874} \\
\hline -no complication & $1(3.1)$ & $3(9.4)$ & $2(6.5)$ & $2(6.3)$ & $3(9.7)$ & \\
\hline $\begin{array}{l}- \text {-HI type } 1 \\
\text {-HI tyne? }\end{array}$ & $1(3.1)$ & $1(3.1)$ & $1(3.2)$ & $2(6.3)$ & $3(9.7)$ & \\
\hline $\begin{array}{l}\text {-HI type } 2 \\
-\mathrm{PH} \text { type } 1\end{array}$ & $1(3.1)$ & 193.1) & $2(6.5)$ & $0(0.0)$ & $1(3.2)$ & \\
\hline $\begin{array}{l}\text {-PH type } 1 \\
\text {-PH type } 2\end{array}$ & $0(0.0)$ & $0(0.0)$ & $1(3.2)$ & $1(3.1)$ & $296.5)$ & \\
\hline $\begin{array}{c}\text { Maximal SBP within } 24 \\
\text { h after r-tPA (mmHg) }\end{array}$ & $144(123-156)$ & $145(125-160)$ & $145(134-166)$ & $151(139-169)$ & $143(134-160)$ & 0.536 \\
\hline Maximal DBP within & & & & & & \\
\hline $\begin{array}{c}24 \mathrm{~h} \text { after r-tPA } \\
(\mathrm{mmHg})\end{array}$ & $80(72-90)$ & $80(72-89)$ & $80(70-90)$ & $80(70-85)$ & $77(70-80)$ & 0.694 \\
\hline $\begin{array}{l}\text { Fasting glucose } \\
(\mathrm{mmol} / \mathrm{L})\end{array}$ & $6.5(5.5-7.3)$ & $6.2(5.4-7.0)$ & $6.1(5.4-8.2)$ & $6.8(5.5-7.9)$ & $6.9(5.9-8.2)$ & 0.491 \\
\hline Creatinine $(\mu \mathrm{mol} / \mathrm{L})$ & 82 (65-94) & $74(63-100)$ & 77 (69-97) & 82 (71-91) & $76(65-93)$ & 0.892 \\
\hline $\mathrm{WBC}\left(\times 10^{9} / \mathrm{L}\right)$ & $7.1(6.0-8.7)$ & $7.8(6.6-8.8)$ & $7.5(5.4-9.2)$ & $8.2(6.9-10.9)$ & $8.9(6.4-11.5)$ & 0.145 \\
\hline
\end{tabular}

Values are presented as $n(\%)$, mean \pm standard deviation, median and interquartile range. Abbreviations: BMI—body mass index, DBPdiastolic blood pressure, IVT—intravenous thrombolysis, HI-hemorrhagic infarction, mRS—modified Rankin scale, MT—mechanical thrombectomy, NIHSS - National Institutes of Health Stroke Scale, PH—parenchymal hematoma, r-tPA—recombinant tissue plasminogen activator, SBP - systolic blood pressure, and WBC-white blood cells count. Q1-Q5 denotes five groups according to the quintile of CRP $(\mathrm{mg} / \mathrm{L})$.

The median CRP 12-24 $\mathrm{h}$ after IVT was $3.94(2.01-5.12 \mathrm{mg} / \mathrm{L})$ and $15.2 \%(n=24)$ of patients had CRP $>10 \mathrm{mg} / \mathrm{L}$. The BMI, NIHSS score on admission and after IVT and prevalence of hypertension increased with the increase in CRP. The median WBC was $7.76\left(6.40-9.61 \times 10^{9} / \mathrm{L}\right)$. Large-vessel disease stroke was associated with a higher WBC (Supplemental Table S1). There was no correlation between CRP and fasting glucose levels $(\mathrm{r}=0.11, p=0.167)$.

3.2. Serum CRP Levels and WBC 12-24 h after IVT and Poor Functional Outcome on Discharge and at Day 90 after Stroke

Patients with poor functional outcome on discharge $(n=52,32.9 \%)$ and at day 90 after stroke $(n=39,25.3 \%)$ had higher CRP measured fasting between 12 and $24 \mathrm{~h}$ after IVT compared with the remainder $(5.92(3.31-12.10)$ vs. $3.16(1.76-5.73) \mathrm{mg} / \mathrm{L}, p<0.001$ and 5.91 (2.87-11.27) vs. $3.43(1.71-5.96) \mathrm{mg} / \mathrm{L}, p<0.001$, respectively). The area under the receiver operating characteristic curve (AUC) of CRP for predicting poor functional outcome at day 90 was 0.667 (95\% CI, 0.559-0.773, $p=0.002)$. With a cut-off point of $8.65 \mathrm{mg} / \mathrm{L}$, the sensitivity, specificity and accuracy were $43.6 \%, 89.6 \%$ and $77.9 \%$, respectively. The frequency of poor functional outcome on discharge and at day 90 was 3.8-fold and 5.8fold higher for patients with CRP $\geq 8.65 \mathrm{mg} / \mathrm{L}$ (the fifth quintile of CRP), respectively, compared with the first quintile $(<1.71 \mathrm{mg} / \mathrm{L})$ (Figure 1). The odds ratio of poor functional outcome for patients in the highest quintile of CRP on discharge remained significant after adjustment for age, sex, BMI, hypertension, mRS score before stroke $>0$, baseline NIHSS score, hemorrhagic brain complications and fasting hyperglycemia (Table 2). The association between CRP and poor functional outcome at day 90 after stroke was significant in the multivariable model adjusted for multiple confounders including age, sex, baseline 
NIHSS score, bleeding brain complications and mechanical thrombectomy (Table 2). The $\mathrm{CRP} \geq 8.65 \mathrm{mg} / \mathrm{L}$ was predicted by the NIHSS score on admission and hypertension (Supplemental Table S2).

There was no significant association between the quartiles of WBC and the frequency of poor functional outcome on discharge and at day 90 (Figure 1).
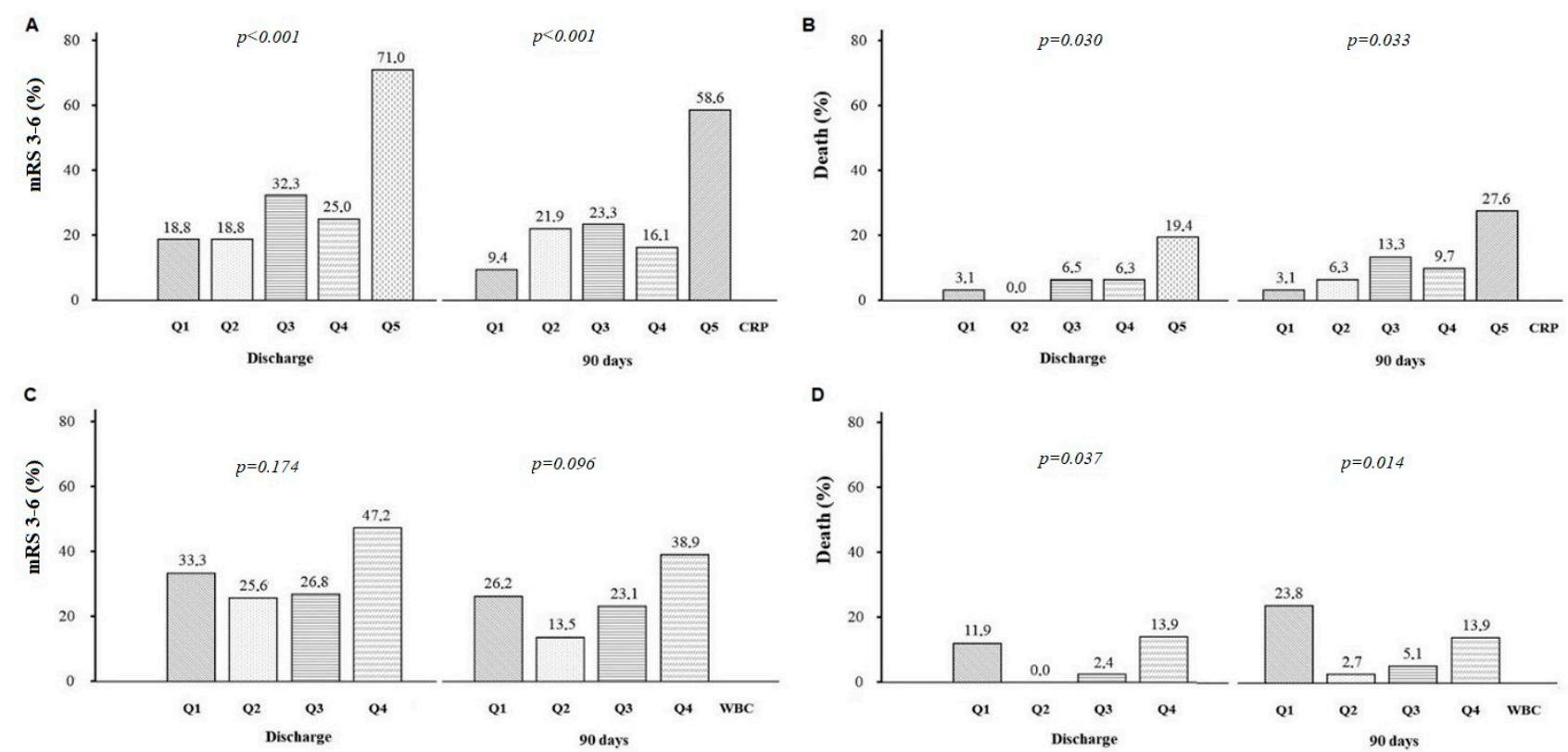

Figure 1. Panel (A,B). The proportion of patients with disability (modified Rankin Scale, mRS 3-6) or death (mRS $=6)$ on discharge and at day 90 after stroke onset, according to the quintile (quintile 1-quintile 5, Q1-Q5) of C-reactive protein (CRP) values. Panel (C,D). The proportion of patients with disability or death on discharge and at day 90 after stroke onset, according to the quartile (quartile 1-quartile 4, Q1-Q4) of white blood cell count (WBC).

Table 2. C-reactive protein and poor functional outcome (mRS 3-6) on discharge and at day 90 after stroke.

\begin{tabular}{|c|c|c|c|c|c|}
\hline \multicolumn{2}{|l|}{ On Discharge } & \multicolumn{2}{|c|}{ Model 1} & \multicolumn{2}{|c|}{ Model 2A } \\
\hline & Events $n,(\%)$ & OR $(95 \%$ CI $)$ & $p$-value & OR $(95 \%$ CI $)$ & $p$-value \\
\hline $\mathrm{Q} 1(<1.71, n=32)$ & $6(18.8)$ & 1.00 (reference) & - & 1.00 (reference) & - \\
\hline Q2 $(1.71-3.11, n=32)$ & $6(18.8)$ & $1.00(0.28-3.56)$ & 1.00 & $1.28(0.27-5.96)$ & 0.756 \\
\hline Q3 $(3.12-5.09, n=31)$ & $10(32.3)$ & $2.13(0.66-6.94)$ & 0.209 & $1.65(0.40-6.86)$ & 0.493 \\
\hline Q4 (5.10-8.64, $n=32)$ & $8(25.0)$ & $1.33(0.40-4.45)$ & 0.647 & $1.02(0.24-4.29)$ & 0.982 \\
\hline Q5 $(\geq 8.65, n=31)$ & $22(71.0)$ & $9.70(2.94-31.98)$ & $<0.001$ & $10.68(2.54-44.83)$ & 0.001 \\
\hline $\mathrm{P}$ for trend & & & $<0.001$ & & 0.004 \\
\hline AIC & & & 182.19 & & 132.89 \\
\hline AUC & & & $0.744 \pm 0.05$ & & $0.895 \pm 0.03$ \\
\hline R2 Nagelkerke & & & 0.241 & & 0.560 \\
\hline Hosmer-Lemeshow test $p$-value & & & 0.369 & & 0.057 \\
\hline \multirow[t]{2}{*}{ At day 90 after stroke } & & \multicolumn{2}{|c|}{ Model 1} & \multicolumn{2}{|c|}{ Model 2B } \\
\hline & Events $n,(\%)$ & OR $(95 \%$ CI) & $p$-value & OR $(95 \%$ CI) & $p$-value \\
\hline Q1 $(<1.71, n=32)$ & $3(9.4)$ & 1.00 (reference) & - & 1.00 (reference) & - \\
\hline Q2 $(1.71-3.11, n=32)$ & $7(21.9)$ & $2.90(0.65-13.0)$ & 0.165 & $4.11(0.73-23.7)$ & 0.109 \\
\hline Q3 $(3.12-5.09, n=31)$ & $7(22.5)$ & $3.18(0.71-14.4)$ & 0.132 & $1.86(0.33-10.63)$ & 0.484 \\
\hline Q4 $(5.10-8.64, n=32)$ & $5(15.7)$ & $1.64(0.34-7.83)$ & 0.535 & $0.75(0.12-4.53)$ & 0.754 \\
\hline Q5 $(\geq 8.65, n=31)$ & $17(54.8)$ & $12.56(2.95-53.5)$ & 0.001 & $7.21(1.44-36.0)$ & 0.016 \\
\hline
\end{tabular}


Table 2. Cont.

\begin{tabular}{ccc}
\hline On Discharge & Model 1 & Model 2A \\
\hline P for trend & 0.022 & 0.021 \\
AIC & 152.42 & 125.16 \\
AUC & $0.776 \pm 0.04$ & $0.887 \pm 0.03$ \\
R2 Nagelkerke & 0.291 & 0.521 \\
Hosmer-Lemeshow test $p$-value & 0.169 & 0.569 \\
\hline
\end{tabular}

Model 1 included age, sex and BMI. Model 2A included age, sex, BMI, hypertension, mRS score before stroke $>0$, baseline NIHSS score, hemorrhagic brain complications and fasting hyperglycemia. Model 2B included age, sex, BMI, hypertension, maximal SBP within $24 \mathrm{~h}$ after r-tPA, mRS score before stroke $>0$, baseline NIHSS score, hemorrhagic brain complications and mechanical thrombectomy. Abbreviations, see Table 1. AIC denotes Akaike information criterion, AUC—-the area under the curve, CI—confidence interval, OR-odds ratio, Q1-Q5 five groups according to the quintile of CRP $(\mathrm{mg} / \mathrm{L})$.

\subsection{Serum CRP Levels and WBC 12-24 h after IVT and Early Neurological Deterioration and Bleeding}

Neurological deterioration after IVT, defined as an increase of two or more points in the NIHSS scale [25] between admission and 12-24 $\mathrm{h}$ after IVT, was observed in seven $(4.43 \%)$ patients. The CRP and WBC values did not differ between groups with and without neurological deterioration (5.77 (3.45-9.31) vs. 3.79 (1.03-7.36) $\mathrm{mg} / \mathrm{L}, p=0.22$ and 10.42 (4.95-13.95) vs. $7.77(6.44-9.77) \times 10^{9} / \mathrm{L}, p=0.29$, respectively). Intracranial bleeding (ECASS class 1-4) was observed in $28(17.72 \%)$ patients $(6.96 \%, 5.06 \%, 3.16 \%$ and $2.53 \%$ for classes 1-4, respectively). We observed a trend toward higher CRP (5.18 (2.99-9.44) vs. 3.56 $(1.84-7.34) \mathrm{mg} / \mathrm{L}), p=0.09)$, and no difference in WBC (7.12 (6.11-10.38) vs. 7.86 (6.51-9.45) $\left.\times 10^{9} / \mathrm{L}, p=0.43\right)$, in patients with and without bleeding, ECASS class $1-4$.

\subsection{Serum CRP Levels and WBC 12-24 h after IVT and In-Hospital and 90-Day Mortality}

Patients who died in hospital $(n=11,7.0 \%)$ and within 90 days after stroke $(n=18$, $11.4 \%$ ) had higher CRP levels compared with the survivors (8.99 (4.39-15.42) vs. 3.67 (1.93$6.93) \mathrm{mg} / \mathrm{L}, p=0.01$ and 6.51 (4.39-10.67) vs. 3.49 (1.83-6.23) $\mathrm{mg} / \mathrm{L}, p=0.006$, respectively). The frequency of in-hospital death was 6.3-fold higher for patients with the fifth quintile of CRP as compared with the first quintile (Figure 1). In-hospital mortality was independently predicted by CRP $\geq 8.65 \mathrm{mg} / \mathrm{L}$ and hemorrhagic brain complications (Table 3). The independent predictors of 90-day mortality were WBC $<6.4 \times 10^{9} / \mathrm{L}$, baseline NIHSS score and hemorrhagic brain complications, but not CRP $\geq 8.65 \mathrm{mg} / \mathrm{L}$ (Table 3 ).

Table 3. Predictors of death on discharge and at day 90 after stroke.

\begin{tabular}{|c|c|c|c|c|c|c|}
\hline On Discharge & OR & $95 \%$ CI & $p$-Value & OR & $95 \% \mathrm{CI}$ & $p$-Value \\
\hline Age (per 1 year) & 1.00 & $0.96-10.5$ & 0.861 & - & - & - \\
\hline Sex (female) & 4.32 & $0.90-20.68$ & 0.067 & - & - & - \\
\hline BMI (per 1 unit) & 1.05 & $0.92-1.21$ & 0.441 & - & - & - \\
\hline Baseline NIHSS score (per 1 point) & 1.15 & $1.03-1.28$ & 0.012 & - & - & - \\
\hline Mechanical thrombectomy & 3.10 & $0.90-10.73$ & 0.074 & - & - & - \\
\hline Hemorrhagic brain complications (ECASS 1-3 score) & 6.82 & $1.91-24.28$ & 0.003 & 5.66 & $1.52-21.11$ & 0.010 \\
\hline $\mathrm{CRP} \geq 8.65 \mathrm{mg} / \mathrm{L}$ & 5.86 & $1.66-20.70$ & 0.006 & 4.79 & $1.29-17.88$ & 0.020 \\
\hline $\mathrm{WBC}<6.4 \times 10^{9} / \mathrm{L}$ & 2.48 & $0.71-8.59$ & 0.152 & - & - & - \\
\hline AIC & & & & & & 72.21 \\
\hline AUC & & & & & & $0.794 \pm 0.07$ \\
\hline R2 Nagelkerke & & & & & & 0.208 \\
\hline Hosmer-Lemeshow test $p$-value & & & & & & 0.689 \\
\hline At day 90 after stroke & OR & $95 \%$ CI & $p$-value & OR & $95 \%$ CI & $p$-value \\
\hline Age (per 1 year) & 1.03 & $0.99-1.08$ & 0.161 & - & - & - \\
\hline Sex (female) & 3.50 & $1.10-11.18$ & 0.034 & - & - & - \\
\hline BMI (per 1 unit) & 1.04 & $0.93-1.16$ & 0.523 & - & - & - \\
\hline
\end{tabular}


Table 3. Cont.

\begin{tabular}{|c|c|c|c|c|c|c|}
\hline On Discharge & OR & $95 \%$ CI & $p$-Value & OR & $95 \% \mathrm{CI}$ & $p$-Value \\
\hline Baseline NIHSS score (per 1 point) & 1.17 & $1.07-1.28$ & $<0.001$ & 1.13 & $1.01-1.25$ & 0.036 \\
\hline Hemorrhagic brain complications (ECASS $1-3$ score) & 8.19 & $2.86-23.50$ & $<0.001$ & 5.53 & $1.59-19.25$ & 0.007 \\
\hline $\mathrm{CRP} \geq 8.65 \mathrm{mg} / \mathrm{L}$ & 4.38 & $1.55-12.39$ & 0.005 & - & - & - \\
\hline $\mathrm{WBC}<6.4 \times 10^{9} / \mathrm{L}$ & 4.06 & $1.48-11.16$ & 0.007 & 5.00 & $1.49-16.78$ & 0.009 \\
\hline AIC & & & & & & 87.03 \\
\hline AUC & & & & & & $0.877 \pm 0.04$ \\
\hline R2 Nagelkerke & & & & & & 0.406 \\
\hline Hosmer-Lemeshow test $p$-value & & & & & & 0.420 \\
\hline
\end{tabular}

Abbreviations, see Tables 1 and 2.

The AUC of WBC for 90-day mortality was 0.660 (95\% CI, 0.518-0.802, $p=0.027$ ). The WBC value of $6.4 \times 10^{9} / \mathrm{L}$ offered the best overall sensitivity, specificity and accuracy of $76.5,23.5$ and $74.0 \%$, respectively. The $\mathrm{WBC}<6.4 \times 10^{9} / \mathrm{L}$ was associated with a 4.7-fold and 8.8-fold higher rate of deaths compared with the WBC 6.40-7.75 $\times 10^{9} / \mathrm{L}$ and 7.76$9.60 \times 10^{9} / \mathrm{L}$ (Figure 1$)$. The $\mathrm{WBC}<6.4 \times 10^{9} / \mathrm{L}$ was predicted by large vessel stroke etiology (Supplemental Table S3).

\section{Discussion}

The current study supported an association between fasting CRP levels measured 12-24 h after IVT and analyzed in quintiles and long-term functional outcome after AIS in patients without concomitant infection. Previous prospective study performed on a large cohort of more than 3000 patients confirmed the prognostic significance of CRP measured within $24 \mathrm{~h}$ from symptom onset in the whole group of patients assessed with mRS three months after AIS, and, admittedly, after adjustment for IVT, this association was still maintained [6]. A similar conclusion came from the study evaluating 436 AIS patients without infection in China, in which elevated CRP levels within $24 \mathrm{~h}$ after IVT were found to increase nearly 5-fold the risk of 3-month poor functional outcome [7]. On the other hand, in the study of Karlinski et al., also evaluating AIS patients without infection, CRP assessed within $24 \mathrm{~h}$ from symptom onset was not associated with 3-month outcome, however, patients were dichotomized according to the abnormal level of CRP, that is, lower than or above $5 \mathrm{ng} / \mathrm{mL}$ [16]. In another study, the change in CRP between admission and the seventh day of hospitalization did not affect long-term outcome either [11]. However, the long-term prognostic role of CRP in AIS patients without infection treated with IVT seemed to be also supported by the studies in patients undergoing another reperfusion therapy of AIS, that is, mechanical thrombectomy. In a recent study, a similar to our research cut-off level of CRP was found to be associated with long-term outcome in AIS patients who underwent endovascular therapy independent of other variables [26].

In our study, no association between CRP levels and 3-month mortality after AIS treated with IVT was found. Our conclusions stayed in line with the previous results coming from the Chinese study which also did not support a correlation of CRP with all-cause mortality at 3 months [7]. Interestingly, in the same study, high WBC increased 2-fold the risk of death at 3 months [7]. Increased WBC the next day after mechanical thrombectomy was found to significantly correlate with the NIHSS score at day 90 after stroke onset [27]. We found instead that the lowest WBC quartile was an independent risk factor for increased long-term mortality at 3 months in AIS patients without infection. Together with the observed trend for higher mortality in the quartile of the highest WBC, it seemed that the association between WBC and the risk of death might resemble the U-curve.

In our specific group of patients, the association of CRP with short-term outcome was also revealed. Our observation resembled the results from another Chinese study which searched for the predictors of poor response to IVT [28]. The authors proposed even the ACBS scale, as there were four parameters which remained significant in the 
multivariate analysis, with CRP apart from age, glucose levels and systolic blood pressure at baseline [28]. Elevated CRP levels were also found to correlate negatively with the reduction in neurological deficit measured with the NIHSS 12-24 h after IVT [29]. Thus, it seems that assessment of CRP within the first $24 \mathrm{~h}$ after admission in AIS patients without infection treated with IVT could be helpful in the evaluation of their short-term clinical outcome. However, uncertainty exists concerning the appropriate time point for CRP measurement in AIS patients. Most previous studies assessed CRP levels within $24 \mathrm{~h}$ after admission [16], whereas in others measurements took place within $24 \mathrm{~h}$ from AIS onset [6] or upon arrival to the emergency department [28]. In our study, we used the specific time frame for CRP assessment, that is, between 12 and $24 \mathrm{~h}$ after IVT, which was previously used in another study evaluating the prognostic role of trends in CRP levels [29]. Another study on a group of more than a thousand AIS patients receiving IVT showed that CRP levels assessed within $24 \mathrm{~h}$ from admission or in the following days better predicted long-term functional outcome that the admission values [30]. It is worth mentioning that in reference to another blood parameter such as glucose, its values measured fasting the next morning after admission had more potent long-term prognostic significance than the admission values [22]. Therefore, as levels of CRP might be biased by food intake [17], we measured CRP levels in our AIS patients after at least $6 \mathrm{~h}$ overnight fasting [21], according to our institutional protocol [22]

There were no associations between CRP levels and neurological worsening or bleeding brain complications in our study. Previous studies showed that patients with elevated CRP more often suffered from bleeding brain complications, however, this association was not confirmed after adjustment for other clinical parameters, including age, stroke severity and recent infection [16], which resembles the results of our study. As to neurological deterioration, higher CRP levels were found to be associated with its increased risk in another study after adjustment for multiple confounders [6] that was not confirmed in our study, probably due to the smaller sample size. In another study, the association between CRP and neurological deterioration was supported only for AIS patients who did not receive IVT [31].

The role of CRP in the pathophysiology of stroke is complicated, however, during AIS, systemic inflammation is induced, which may result in increased body temperature, WBC and CRP levels [32]. In a rabbit model of stroke, CRP levels after a cerebrovascular event correlated with the size of the infarct, and were perceived by the authors as a good marker of prognosis during AIS assessment [33]. Early treatment with IVT may result in the reduction in inflammatory response due to inhibition of the brain tissue necrosis [32].

In our study, CRP after adjustment for numerous variables including hypertension predicted poor functional outcomes. Interestingly, we observed that hypertension was the strongest predictor of the highest levels of CRP in the multivariate analysis (Supplemental Table S2). We hypothesize that elevated CRP may reflect the risk of an unfavorable outcome that was attributed to hypertension in other studies [34]. Future studies are needed to evaluate those mechanisms. Although there was no statistically significant correlation between CRP and fasting glucose levels, we cannot exclude the true correlation with the increase in the sample size.

Non-infective CRP in patients with AIS may deliver prognostic information distinct from that carried by CRP measured during the acute phase of infection. Non-infective CRP elevation may reflect stroke-induced inflammation and endothelial dysfunction contributing to a hypercoagulable state and extensive tissue damage. High levels of CRP are an independent marker of cardiovascular risk, which may be reduced by a statin therapy independently to a lipid-lowering drug action [35]. Aimed anti-inflammatory treatment targeting interleukin-1, endothelial selectins and leukocyte infiltration shows promising results in preclinical and small clinical studies in AIS [36]. Therefore, we view the results of our study as hypothesis-generating, whereas future studies are needed to evaluate whether such treatment could be effective in diminishing inflammatory processes induced by AIS and manifested by non-infective CRP increase. Finally, the unique timing 
of sample collections that takes into consideration the CRP-kinetics may contribute to our observations.

Our study has important limitations. First, the sample of patients was relatively small and therefore subgroup analyses, especially related to WBC, should be interpreted with caution. Second, we did not analyze the influence of change in CRP levels during hospitalization on long-term functional outcome. Third, we also did not take into account the differential of WBC which was recently shown to be an important prognostic factor in AIS patients [37]. Fourth, the reported statistical associations do not necessarily mean a cause-effect relationship.

\section{Conclusions}

In conclusion, CRP levels measured fasting between 12 and $24 \mathrm{~h}$ after IVT are an independent risk factor for poor short- and long-term outcomes in AIS patients without infection, as well as for in-hospital mortality. The lowest quartile of WBC predicts 3month mortality; however, this finding needs further investigation. Future studies are also expected to create a prognostic scale for short- and long-term prognosis after AIS with CRP as one of the reasonable parameters.

Supplementary Materials: The following are available online at https://www.mdpi.com/article/ 10.3390/jcm10081610/s1. Supplementary Table S1. Baseline clinical characteristics of the patients based on white blood cell count (WBC) quartiles; Supplementary Table S2. Predictors of the CRP $\geq 8.65 \mathrm{mg} / \mathrm{L}$ (fifth quintile); Supplementary Table S3. Predictors of white blood cells count $<6.4 \times 10^{9} /$ L (first quartile).

Author Contributions: M.W. (conceptualization, methodology, draft writing and editing), J.D. (data acquisition), L.D. (formal analysis, methodology, draft writing and editing) and A.S. (supervision and draft review). All authors have read and agreed to the published version of the manuscript.

Funding: This research was funded by the grant from The National Centre for Research and Development, Poland under the ERA-NET NEURON program, contract no.: ERA-NET-NEURON/21/2020 and from the Jagiellonian University grant N41/DBS/000464.

Institutional Review Board Statement: The study was conducted according to the guidelines of the Declaration of Helsinki, and approved by the Jagiellonian University Ethical Committee (KBET/54/B/2007).

Informed Consent Statement: We obtained informed consent from all patients which was either written or verbal in the presence of at least two physicians in case of the inability to use the dominant hand due to stroke.

Data Availability Statement: The data supporting the findings of the present study will be made available for any qualified investigator from the corresponding author upon reasonable request.

Conflicts of Interest: The authors declare no conflict of interest.

\section{References}

1. Wnuk, M.; Pera, J.; Jagiełła, J.; Szczygieł, E.; Ferens, A.; Spisak, K.; Wołkow, P.; Kmieć, M.; Burkot, J.; Chrzanowska-Waśko, J.; et al. The rs2200733 variant on chromosome 4q25 is a risk factor for cardioembolic stroke related to atrial fibrillation in Polish patients. Neurol. Neurochir. Pol. 2011, 45, 148-152. [CrossRef]

2. Drabik, L.; Konieczyńska, M.; Undas, A. Clot Lysis Time Predicts Stroke During Anticoagulant Therapy in Patients with Atrial Fibrillation. Can. J. Cardiol. 2020, 36, 119-126. [CrossRef]

3. Soeki, T.; Sata, M. Inflammatory Biomarkers and Atherosclerosis. Int. Heart J. 2016, 57, 134-139. [CrossRef] [PubMed]

4. Milwidsky, A.; Ziv-Baran, T.; Letourneau-Shesaf, S.; Keren, G.; Taieb, P.; Berliner, S.; Shacham, Y. CRP velocity and short-term mortality in ST segment elevation myocardial infarction. Biomarkers 2017, 22, 383-386. [CrossRef]

5. Zhao, X.; Jiang, L.; Xu, L.; Tian, J.; Xu, Y.; Zhao, Y.; Feng, X.; Wu, Y.; Zhang, Y.; Wang, D.; et al. Predictive value of in-hospital white blood cell count in Chinese patients with triple-vessel coronary disease. Eur. J. Prev. Cardiol. 2019, 26, 872-882. [CrossRef] [PubMed]

6. Matsuo, R.; Ago, T.; Hata, J.; Wakisaka, Y.; Kuroda, J.; Kuwashiro, T.; Kitazono, T.; Kamouchi, M.; on behalf of the Fukuoka Stroke Registry Investigators. Plasma C-Reactive Protein and Clinical Outcomes after Acute Ischemic Stroke: A Prospective Observational Study. PLoS ONE 2016, 11, e0156790. [CrossRef] 
7. Qu, X.; Shi, J.; Cao, Y.; Zhang, M.; Xu, J. Prognostic Value of White Blood Cell Counts and C-reactive Protein in Acute Ischemic Stroke Patients After Intravenous Thrombolysis. Curr. Neurovasc. Res. 2018, 15, 10-17. [CrossRef]

8. Montaner, J.; Fernandez-Cadenas, I.; Molina, C.A.; Ribó, M.; Huertas, R.; Rosell, A.; Penalba, A.; Ortega, L.; Chacón, P.; AlvarezSabín, J. Poststroke C-Reactive Protein Is a Powerful Prognostic Tool Among Candidates for Thrombolysis. Stroke 2006, 37, 1205-1210. [CrossRef] [PubMed]

9. Topakian, R.; Strasak, A.M.; Nussbaumer, K.; Haring, H.-P.; Aichner, F.T. Prognostic value of admission C-reactive protein in stroke patients undergoing IV thrombolysis. J. Neurol. 2008, 255, 1190-1196. [CrossRef] [PubMed]

10. Winbeck, K.; Poppert, H.; Etgen, T.; Conrad, B.; Sander, D. Prognostic Relevance of Early Serial C-Reactive Protein Measurements After First Ischemic Stroke. Stroke 2002, 33, 2459-2464. [CrossRef]

11. Lee, S.; Song, I.-U.; Na, S.-H.; Jeong, D.-S.; Chung, S.-W. Association Between Long-term Functional Outcome and Change in hs-CRP Level in Patients With Acute Ischemic Stroke. Neurologist 2020, 25, 122-125. [CrossRef]

12. Mendes de Sá, F.; Mendes Bertoncello Fontes, C.; Lia Mondelli, A. Major infections in hospitalized patients with stroke: A pro-spective study. Int. Arch. Med. 2016, 9, 1-8.

13. Derbisz, J.; Nowak, K.; Wnuk, M.; Pulyk, R.; Jagiella, J.; Slowik, J.; Dziedzic, T.; Slowik, A. Prognostic Significance of StrokeAssociated Infection and other Readily Available Parameters in Acute Ischemic Stroke Treated by Intravenous Thrombolysis. J. Stroke Cerebrovasc. Dis. 2021, 30, 105525. [CrossRef]

14. Weimar, C.; Roth, M.P.; Zillessen, G.; Glahn, J.; Wimmer, M.L.; Busse, O.; Haberl, R.L.; Diener, H.-C.; on behalf of the German Stroke Date Bank Collaborators. Complications following Acute Ischemic Stroke. Eur. Neurol. 2002, 48, 133-140. [CrossRef]

15. Sproston, N.R.; Ashworth, J.J. Role of C-Reactive Protein at Sites of Inflammation and Infection. Front. Immunol. 2018, 9, 754. [CrossRef]

16. Karlinski, M.; Bembenek, J.; Grabska, K.; Kobayashi, A.; Baranowska, A.; Litwin, T.; Czlonkowska, A. Routine serum C-reactive protein and stroke outcome after intravenous thrombolysis. Acta Neurol. Scand. 2014, 130, 305-311. [CrossRef] [PubMed]

17. Alam, I.; Gul, R.; Chong, J.; Tan, C.T.Y.; Chin, H.X.; Wong, G.; Doggui, R.; Larbi, A. Recurrent circadian fasting (RCF) improves blood pressure, bi-omarkers of cardiometabolic risk and regulates inflammation in men. J. Transl. Med. 2019, 17, 272. [CrossRef] [PubMed]

18. Tarp, S.; Bartels, E.M.; Bliddal, H.; Furst, D.E.; Boers, M.; Danneskiold-Samsøe, B.; Rasmussen, M.; Christensen, R. Effect of nonsteroidal antiinflammatory drugs on the C-reactive protein level in rheumatoid arthritis: A meta-analysis of randomized controlled trials. Arthritis Rheum. 2012, 64, 3511-3521. [CrossRef]

19. Kościelniak, M.B.K.; Charchut, M.A.; Wójcik, M.M.; Sztefko, K.; Tomasik, P.J. Impact of Fasting on Complete Blood Count Assayed in Capillary Blood Samples. Lab. Med. 2017, 48, 357-361. [CrossRef] [PubMed]

20. Clua-Espuny, J.L.; Abilleira, S.; Queralt-Tomas, L.; Gonzalez-Henares, A.; Gil-Guillen, V.; Muria-Subirats, E.; Ballesta-Ors, J. Long-Term Survival After Stroke According to Reperfusion Therapy, Cardiovascular Therapy and Gender. Cardiol. Res. 2019, 10, 89-97. [CrossRef]

21. Nordestgaard, B.G.; Langsted, A.; Mora, S.; Kolovou, G.; Baum, H.; Bruckert, E.; Watts, G.F.; Sypniewska, G.; Wiklund, O.; Boren, J.; et al. Fasting is not routinely required for determination of a lipid profile: Clinical and laboratory implications including flagging at desirable concentration cut-points-A joint con-sensus statement from the European Atherosclerosis Society and European Fede. Eur. Heart J. 2016, 37, 1944-1958. [CrossRef] [PubMed]

22. Wnuk, M.; Popiela, T.; Drabik, L.; Brzegowy, P.; Lasocha, B.; Wloch-Kopec, D.; Pulyk, R.; Jagiella, J.; Wiacek, M.; Kaczorowski, R.; et al. Fasting Hyperglycemia and Long-term Outcome in Patients with Acute Ischemic Stroke Treated with Mechanical Thrombectomy. J. Stroke Cerebrovasc. Dis. 2020, 29, 104774. [CrossRef] [PubMed]

23. Trouillas, P.; Von Kummer, R. Classification and Pathogenesis of Cerebral Hemorrhages After Thrombolysis in Ischemic Stroke. Stroke 2006, 37, 556-561. [CrossRef]

24. Undas, A.; Drabik, L.; Potpara, T. Bleeding in anticoagulated patients with atrial fibrillation: Practical considerations. Pol. Arch. Intern. Med. 2020, 130, 47-58. [CrossRef] [PubMed]

25. Kwan, J.; Hand, P. Early neurological deterioration in acute stroke: Clinical characteristics and impact on outcome. QJM 2006, 99, 625-633. [CrossRef] [PubMed]

26. Wang, L.; Wu, L.; Lang, Y.; Wu, D.; Chen, J.; Zhao, W.; Li, C.; Ji, X. Association between high-sensitivity C-reactive protein levels and clinical outcomes in acute ischemic stroke patients treated with endovascular therapy. Ann. Transl. Med. 2020, 8, 1379. [CrossRef]

27. Huber, T.; Kleine, J.F.; Kaesmacher, J.; Bette, S.; Poppert, H.; Zimmer, C.; Boeckh-Behrens, T. Blood Leukocytes as Prognostic Parameter in Stroke Thrombectomy. Cerebrovasc. Dis. 2016, 42, 32-40. [CrossRef]

28. Yue, Y.-H.; Li, Z.-Z.; Hu, L.; Zhu, X.-Q.; Xu, X.-S.; Sun, H.-X.; Wan, Z.-W.; Xue, J.; Yu, D.-H. Clinical characteristics and risk score for poor clinical outcome of acute ischemic stroke patients treated with intravenous thrombolysis therapy. Brain Behav. 2019, 9, e01251. [CrossRef]

29. Gill, D.; Sivakumaran, P.; Wilding, P.; Love, M.; Veltkamp, R.; Kar, A. Trends in C-Reactive Protein Levels Are Associated with Neurological Change Twenty-Four Hours after Thrombolysis for Acute Ischemic Stroke. J. Stroke Cerebrovasc. Dis. 2016, 25, 1966-1969. [CrossRef]

30. Rocco, A.; Ringleb, P.A.; Grittner, U.; Nolte, C.H.; Schneider, A.; Nagel, S. Follow-up C-reactive protein level is more strongly associ-ated with outcome in stroke patients than admission levels. Neurol. Sci. 2015, 36, 2235-2241. [CrossRef] 
31. Seo, W.-K.; Seok, H.-Y.; Kim, J.H.; Park, M.-H.; Yu, S.-W.; Oh, K.; Koh, S.-B.; Park, K.-W. C-Reactive Protein is a Predictor of Early Neurologic Deterioration in Acute Ischemic Stroke. J. Stroke Cerebrovasc. Dis. 2012, 21, 181-186. [CrossRef] [PubMed]

32. Ye, L.; Cai, R.; Yang, M.; Qian, J.; Hong, Z. Reduction of the systemic inflammatory induced by acute cerebral infarction through ultra-early thrombolytic therapy. Exp. Ther. Med. 2015, 10, 1493-1498. [CrossRef]

33. Yu, Q.; Lin, Y.; Yang, P.; Wang, Y.; Zhao, S.; Yang, P.; Fan, J.; Liu, E. C-reactive protein is associated with the progression of acute embolic stroke in rabbit model. J. Thromb. Thrombol. 2011, 33, 301-307. [CrossRef] [PubMed]

34. Zhang, Q.; Qiu, D.-X.; Fu, R.-L.; Xu, T.-F.; Jing, M.-J.; Zhang, H.-S.; Geng, H.-H.; Zheng, L.-C.; Wang, P.-X. H-Type Hypertension and C Reactive Protein in Recurrence of Ischemic Stroke. Int. J. Environ. Res. Public Health 2016, 13, 477. [CrossRef]

35. Drieu, A.; Levard, D.; Vivien, D.; Rubio, M. Anti-inflammatory treatments for stroke: From bench to bedside. Ther. Adv. Neurol. Disord. 2018, 11, 1-15. [CrossRef] [PubMed]

36. Dinarello, C.A.; Simon, A.; Van Der Meer, J.W.M. Treating inflammation by blocking interleukin-1 in a broad spectrum of diseases. Nat. Rev. Drug Discov. 2012, 11, 633-652. [CrossRef]

37. Xue, J.; Huang, W.; Chen, X.; Li, Q.; Cai, Z.; Yu, T.; Shao, B. Neutrophil-to-Lymphocyte Ratio Is a Prognostic Marker in Acute Ischemic Stroke. J. Stroke Cerebrovasc. Dis. 2017, 26, 650-657. [CrossRef] 